\title{
Análise do Programa Nacional de Capacitação com Gestores Ambientais de Sergipe na visão dos participantes
}

\author{
Analysis of the National Training Program with Environmental Managers of Sergipe \\ in the view of participants
}

\section{Analyse du Programme National de Formation avec Gestionnaires de L'environnement de Sergipe dans la vue des participants} \author{
participantes \\ Rafael Fragassi Oliveira* \\ (rafael_fragassi@hotmail.com) \\ Carina Angélica dos Santos* \\ (profcarina@yahoo.com.br) \\ Laura Jane Gomes* \\ (laurabuturi@gmail.com)
}

Análisis del Programa Nacional de Formación en Gerentes Ambiental Sergipe, en vista de los

Recebido em 25/02/2015; revisado e aprovado em 14/06/2015; aceito em 23/07/2015

DOI: http://dx.doi.org/10.1590/151870122015212

\begin{abstract}
Resumo: Este trabalho teve por objetivo analisar o Programa Nacional de Capacitação (PNC) com Gestores Ambientais do Estado de Sergipe na visão dos participantes. Foi aplicado um questionário semiestruturado enviado virtualmente. Paralelamente ao envio do questionário, as 230 pessoas cadastradas foram contatadas por meio de ligação telefônica. Constatou-se que nem todos os entrevistados que possuem nível superior tiveram formação na área ambiental. Tal seleção deveria estar atrelada à formação do profissional na área ambiental. Quanto às mudanças na gestão ambiental municipal após o PNC, não foi possível quantificar, porém alguns avanços foram apontados.

Palavras-chave: Gestão ambiental. Fortalecimento institucional. SISNAMA.
\end{abstract}

Abstract: This study aimed to analyze the National Training Program (PNC) with Environmental Managers of the State of Sergipe in view of the participants. A semi-structured questionnaire sent virtually was applied. In parallel with the circulation of the questionnaire, the 230 people registered were contacted by phone call. The profile of the participants was not what was stipulated by the PNC. This selection should be linked to the training of professionals in the environmental area. As for the changes in municipal environmental management of unicípios participants could not be quantified, but some progress has been noted.

Key words: Management. Strengthening. SISNAMA.

Résumé: Cette étude visait à analyser le Programme National de Formation (PNC) avec les gestionnaires de l'environnement de l'État de Sergipe en vue des participants. Un questionnaire semi-structuré envoyée presque a été appliquée. En parallèle avec la diffusion du questionnaire, les 230 personnes inscrites ont été contactés par appel téléphonique. Le profil des participants ne était pas ce qui était prévu par la PNC. Cette sélection devrait être liée à la formation des professionnels dans le domaine de l'environnement. En ce qui concerne les changements dans la gestion environnementale municipale de unicípios participants n'a pu être quantifiée, mais certains progrès ont été constatés.

Mots-clés: Gestion. Renforcement. SISNAMA.

Resumen: Este estudio tuvo como objetivo analizar el Programa Nacional de Capacitación (PNC) con los gestores ambientales del Estado de Sergipe, en vista de los participantes. Enviada prácticamente se aplicó un cuestionario semi-estructurado. En paralelo con la circulación del cuestionario, las 230 personas registradas fueron contactados por llamada telefónica. El perfil de los participantes no fue lo que se estipuló por la PNC. Esta selección debe estar vinculado a la formación de profesionales en el área ambiental. En cuanto a los cambios en la gestión ambiental municipal de unicípios participantes no pudieron ser cuantificados, pero se ha observado algún progreso.

Palabras clave: Gestión. Fortalecimiento. SISNAMA.

\section{Introdução}

A Constituição Federal de 1988 (BRASIL, 1988) designou diversas competências comuns a todas as esferas da federação, dentre elas a proteção do meio ambiente. Em seu Artigo 225 é estabelecido que "todos têm direito ao meio ambiente ecologicamente equilibrado, bem de uso comum do povo e essencial à sadia qualidade de vida, atribuindo ao poder público e a coletividade o dever de defendê-lo e preservá-lo para as presentes gerações e futuras" (ANTON, 2007).

Destaca-se, também na Constituição,

* Universidade Federal de Sergipe, Aracajú, Sergipe, Brasil. 
em seu Artigo 23, que cada município deve ficar responsável no que diz a respeito à execução da Gestão Ambiental local com a finalidade de consolidação do SISNAMA. A Lei Complementar $n^{\circ} 140$ assinada em 2011 deixa clara as competências da União, Estados, Distritos e Municípios quanto à proteção de paisagens naturais notáveis; à proteção ao meio ambiente; ao combate à poluição em qualquer de suas formas e à preservação das florestas, da fauna e flora.

Assim, torna-se notória que a prática da descentralização deve concentrar, de forma mais eficiente, o poder de decisão da gestão ambiental "nas mãos" dos municípios. Entretanto, para a consolidação da descentralização, foi elaborado pelo Governo Federal em 2008, o Programa Nacional de Apoio à Gestão Ambiental Municipal (PROGRAM), por meio de cinco eixos: 1. Formação, capacitação e assistência técnica; 2. Comunicação e acesso à formação ambiental e cidadania; 3. Participação e controle social; 4 . Planejamento e monitoramento ambiental e 5. Financiamento da gestão ambiental.

No Estado de Sergipe, a execução da gestão do Meio Ambiente está atualmente concentrada na Secretaria de Estado do Meio Ambiente e dos Recursos Hídricos (SEMARH) e, no ano de 2008, tornou-se integrante do Programa Nacional de Capacitação (PNC), junto com os demais 22 Estados da Federação. O PNC contou com a orientação da Comissão Técnica Tripartite Estadual, com a função de cumprir metas relacionadas ao primeiro eixo: Formação e capacitação e assistência técnica, porém a capacitação só ocorreu de fato no ano de 2010.

O Programa teve a finalidade de estabelecer as bases de estruturação municipal para a gestão ambiental local, incentivando as prefeituras a assumirem suas importantes funções no sistema.

Nesse sentido, julga-se necessário identificar em que medida o PNC contribuiu para o fortalecimento da gestão ambiental nos municípios do Estado de Sergipe e se os agentes que concluíram o curso estão fazendo parte da gestão municipal. Para isso, este trabalho teve como objetivo analisar o Programa Nacional de Capacitação de Gestores Ambientais sob a visão dos participantes bem como conhecer o perfil dos concludentes do PNC do ano 2010.
Objetivou-se também analisar a visão dos participantes quanto à qualidade do curso ministrado, bem como verificar se houve avanços na gestão ambiental dos municípios.

\section{Procedimento metodológico}

\section{1 Área de estudo}

O estudo foi realizado no estado de Sergipe, que está localizado na região nordeste do Brasil e apresenta uma área de 21.910 $\mathrm{km}^{2}$ de extensão com dois biomas predominantes: Mata Atlântica e Caatinga. Na região litorânea, há ocorrência de Mata Atlântica com a predominância de ecossistemas de restingas e manguezais, já no extremo oeste do Estado, ocorre a predominância do bioma Caatinga.

\subsection{Coleta e análise das informações}

O trabalho foi calcado no estudo exploratório, uma vez que nunca foi realizada uma pesquisa sobre a temática no Estado de Sergipe de forma descritiva, de maneira que se propôs analisar o perfil dos participantes do curso e a sua visão em relação às mudanças na gestão ambiental municipal.

$\mathrm{O}$ universo da pesquisa se reportou a todos os participantes do PNC realizado em 2010, no Estado de Sergipe. Estes foram identificados por meio do cadastro de participantes do PNC, disponibilizado pela Superintendência de Qualidade Ambiental, Desenvolvimento e Educação Ambiental (SQS), promotora da capacitação e pertencente à Secretaria de Estado do Meio Ambiente e dos Recursos Hídricos. No referido cadastro, os nomes dos gestores participantes estavam distribuídos por territórios: Grande Aracaju, Leste Sergipano, Médio e Alto Sertão, Agreste Sergipano, Sul e Centro Sul Sergipano e Baixo São Francisco (SERGIPE, 2007).

O período da capacitação foi de 12 a 16 , 26 a 30 de abril, 3 a 7 de maio e 5 a 9 de julho do ano de 2010. Segundo consta no cadastro disponibilizado pela SQS/SEMARH, participaram da capacitação 230 gestores, porém não foi possível obter informações de quantos deste total cursaram na forma presencial e quantos participaram do curso virtual. 
Com base em revisões bibliográficas sobre o tema, foi elaborado um questionário semiestruturado, adaptado de Darós (2011), subdividido em partes: Perfil dos Participantes do Programa (idade, sexo, escolaridade); Atuação desses profissionais no momento da realização da pesquisa; Avaliação do entrevistado quanto à capacitação recebida e visão destes sobre os desdobramentos na gestão ambiental municipal após o curso de capacitação.

O questionário foi enviado por e-mail via ferramenta Google docs aos concludentes do curso. Paralelamente ao envio do questionário, as 230 pessoas cadastradas foram contatadas por meio de ligação telefônica. Destas, apenas 91 atenderam a ligação. O contato telefônico teve como objetivos: divulgar a presente pesquisa e saber se receberam o questionário via e-mail, bem como incentiválos a responder, caso não tivessem feito ainda, e atualização do e-mail caso fosse necessário além de checar se ainda estavam presentes na prefeitura na área ambiental.

Foi definida uma amostragem a partir dos 230 nomes cadastrados. A determinação da amostra foi feita com base na fórmula para cálculo do tamanho mínimo da amostra de acordo com Barbetta (2006), onde: N número (número de gestores) $=230 ; \mathrm{n}$ tamanho (número de elementos) da amostra; n0 uma primeira aproximação do tamanho da amostra e E0 erro amostral tolerável = 0,12 (probabilidade de $90 \%$ de significância), definindo-se a amostra mínima com 53 questionários.

$$
\begin{gathered}
\mathrm{n} 0=1 / \mathrm{E}^{2} \\
=1 / 0,12^{2}=69,4 \\
\mathrm{n}=\mathrm{N}^{*} \mathrm{n} 0 /(\mathrm{N}+\mathrm{n} 0) \\
=230 * 69,4 /(230+69,4)
\end{gathered}
$$

n $=53$ (amostra necessária a ser utilizada num erro amostral de 12\%)

Após a realização de um pré-teste, o envio do questionário foi realizado entre os meses de março e julho de 2014. Apesar do contato telefônico e do reenvio dos questionários (oito vezes) aos 230 e-mails disponibilizados pelo cadastro, 67 pessoas responderam ao questionário.

Para análise, os dados das questões fechadas foram sistematizados no programa SPSS e apresentados em forma de gráficos e tabelas com as devidas porcentagens. As respostas abertas foram analisadas de acordo com a metodologia de análise de conteúdo de Bardin (2011). Para isso, fez-se a delimitação dos objetivos da análise das perguntas relacionadas ao Programa. Em seguida, estas, passaram pelo processo de categorização, utilização de termos chave para indicar o significado central das perguntas, e, por fim, a interpretação inferencial das respostas dadas pelos entrevistados, realizando o discurso a partir destas.

Quando as falas foram transcritas de forma integral, o nome dos entrevistados foi substituído por número e uma breve descrição do perfil: sexo e formação profissional.

\section{Resultados e discussões}

\subsection{Perfil dos entrevistados}

Dos 67 entrevistados, 29 (43\%) são do sexo feminino, e 38 (57\%), do sexo masculino. Se comparado com o total de participantes do PNC apresentados no cadastro, verificou-se que 68 são do sexo feminino (29,5\%), e 162 são do sexo masculino $(70,5 \%)$. Pode-se afirmar que vertentes relacionadas ao tema ambiental vêm manifestando um acentuado interesse dos diferentes gêneros em virtude da sua atualidade e democratização participativa (DARÓS, 2011).

Quanto à faixa etária, 12 (18\%) possuem a idade entre 18 e 30 anos; 32 (48\%) entre 30 e 45 anos; 22 (33\%) entre 45 e 60 anos e um (2\%) acima de 60 anos.

De acordo com os resultados obtidos, $43(64,2 \%)$ dos entrevistados possuem ensino superior completo. Apenas dez (15\%) dos participantes possuem o ensino médio completo e dois (3\%), ensino médio incompleto. Convém registrar também que cinco entrevistados $(7,5 \%)$ afirmaram possuir ensino superior incompleto, cinco $(7,5 \%)$ possuem mestrado, e dois (3\%) possuem o título de doutorado.

Quando questionados sobre o local de residência, $55(82,1 \%)$ responderam que residem em área urbana, e $12(17,9 \%)$ dos entrevistados residem em área rural. Fazendo-se uma correlação entre a escolaridade e residência do total de entrevistados, podese observar que, dos 55 entrevistados que residem em área urbana, 36 (54\%) possuem 
ensino superior completo, nove $(14 \%)$ ensino médio completo e cinco (8\%) mestrado. Dos 12 entrevistados que residem em área rural, sete $(11 \%)$ possuem ensino superior completo, dois $(3 \%)$ ensino superior incompleto, um $(1,5 \%)$ ensino médio incompleto, um $(1,5 \%)$ ensino médio completo e um $(1,5 \%)$ doutorado (Quadro 1).

\begin{tabular}{|c|c|c|c|}
\hline \multirow{2}{*}{ Escolaridade X Residência } & Rural & Urbana & \multirow{2}{*}{$\begin{array}{c}\text { Entrevistados } \\
\text { (Número) }\end{array}$} \\
\cline { 2 - 4 } & 1 & 1 & 2 \\
Ensino Médio Incompleto & 1 & 9 & 10 \\
Ensino Médio Completo & 2 & 3 & 5 \\
Ensino Superior Incompleto & 7 & 36 & 43 \\
Ensino Superior Completo & 0 & 5 & 5 \\
Mestrado & 1 & 1 & 2 \\
Doutorado & 12 & 55 & 67 \\
\hline
\end{tabular}

Quadro 1 - Correlação entre a escolaridade e residência, rural e urbana, dos entrevistados que participaram do Programa Nacional de Capacitação em Sergipe, São Cristóvão, 2014.

Fonte: dados da pesquisa.

\section{a) Atuação profissional}

Dos entrevistados, 58 (82\%) afirmam que estão, atualmente, trabalhando, e nove $(18 \%)$ não. Com relação à área de atuação profissional, constatou-se que 33\% possuem empregos relacionados à área ambiental, $46 \%$ não trabalham nessa área, supostamente pelo motivo da mudança de gestão da prefeitura, que ocorre a cada quatro anos, e $21 \%$ não responderam a esse quesito.

Fazendo a correlação entre a escolaridade e o tempo de trabalho na área ambiental dos entrevistados, constatou-se que, dos 67 entrevistados, 21(31,3\%) possuem ensino superior completo e trabalham há mais de cinco anos na área ambiental, três $(4,5 \%)$ possuem mestrado e estão há dois anos trabalhando na área ambiental, sete $(10,5 \%)$ possuem ensino médio completo e trabalham há três anos na área ambiental e, um $(1,5 \%)$ possui ensino superior incompleto e trabalha há três anos na área ambiental. Trinta e cinco entrevistados $(52,2 \%)$ não responderam a esse quesito, supostamente por não estarem atuando na área ambiental (Quadro 2).

\begin{tabular}{|c|c|c|c|}
\hline $\begin{array}{c}\text { Escolaridade X Tempo na Área } \\
\text { Ambiental }\end{array}$ & $\begin{array}{c}\text { Tempo na área } \\
\text { ambiental (anos) }\end{array}$ & Percentual & $\begin{array}{c}\text { Número de } \\
\text { Entrevistados }\end{array}$ \\
\hline Ensino Médio Completo & 3 & $10,5 \%$ & 7 \\
\hline Ensino Superior Completo & Mais de 5 anos & $31,3 \%$ & 3 \\
\hline Mestrado & 2 & $4,5 \%$ & 1 \\
\hline Ensino Superior Incompleto & 3 & $1,5 \%$ & 35 \\
\hline Não responderam & ----- & $52,2 \%$ & 67 \\
\hline Total de Entrevistados & ------ & ----- & 3 \\
\hline
\end{tabular}

Quadro 2 - Correlação entre a escolaridade e tempo de trabalho na área ambiental dos entrevistados que participaram do Programa Nacional de Capacitação em Sergipe, São Cristóvão, 2014.

Fonte: dados da pesquisa.

Quando questionados sobre as experiências na área ambiental, dos entrevistados, nove $(14 \%)$ responderam. Todos possuem ensino superior completo (engenharia ambiental, agronômica e civil; biologia; licenciatura em campo e ciências sociais) e estão há mais de cinco anos trabalhando na área ambiental (educação ambiental, ONG's e licenciamento ambiental, junto ao INCRA/SE).

Convém ressaltar que nem todos os entrevistados que afirmam possuir experiência 
na área ambiental, possuem formação específica nessa área.

Para Darós (2011) as variáveis básicas que buscam constituir um perfil mínimo definido estão relacionadas a escolaridade, cargo e tempo de trabalho na área ambiental, obtendo dessa forma uma base situacional dos servidores nas estruturas ambientais locais além de indiretamente refletir na confiabilidade dos dados.

Quanto às experiências na área profissional, os entrevistados afirmaram que possuem experiência na gestão ambiental pública e no licenciamento ambiental, com um convívio direto com conflitos voltados aos recursos naturais, maior entendimento acerca da importância da educação ambiental e gerenciamento da coleta de resíduos sólidos. Outro ponto destacado foi o desenvolvimento de projetos e palestras nas escolas municipais, maior aptidão de como recuperar matas ciliares degradadas, aliada a mobilização com os produtores rurais das áreas.

\subsection{Satisfação em relação ao Programa Nacional de Capacitação (PNC)}

Quando questionados sobre a satisfação do PNC, constatou-se que $29(43,3 \%)$ classificaram o PNC como bom, 29 (43,3\%) como ótimo, e apenas nove $(13,4 \%)$ classificaram como regular. Vale ressaltar que nenhum dos 67 entrevistados classificou o PNC como péssimo ou ruim (Figura 1).

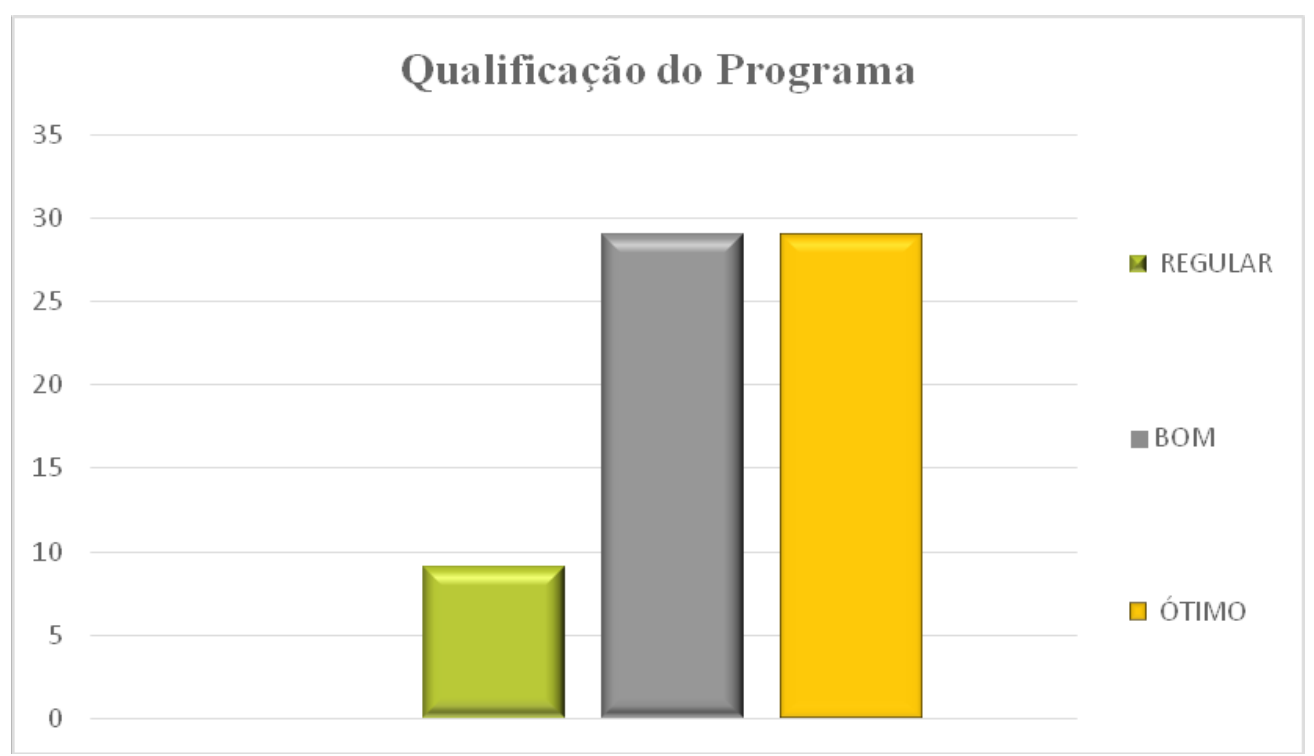

Figura 1 - Satisfação referente a qualificação do Programa Nacional de Capacitação, São Cristóvão, 2014.

Fonte: dados da pesquisa.

Quando questionados sobre qual ou quais dos seis passos estratégicos do PNC os entrevistados consideravam o mais importante, $28(45 \%)$ dos entrevistados responderam que a Capacitação foi a mais importante; 13 $(19 \%)$ responderam apoio a discussão, troca de informações e intercâmbio de experiências; $10(15 \%)$ afirmaram ser a sensibilização e mobilização; seis $(9 \%)$ referiram-se ao tópico Comitê Gestor Local (CGL); três $(4,5)$ fizeram menção à etapa formalização do compromisso de adesão ao PNC e dois (3\%) acompanhamento e avaliação.
Quanto aos benefícios do PNC para o crescimento profissional, dos 67 entrevistados, $62(92 \%)$ responderam à questão. Esses afirmaram que o PNC ampliou o entendimento relacionado ao meio ambiente na área de gestão ambiental, criação, organização e estruturação de uma secretaria. Enfatizaram o maior esclarecimento de como é a atuação do Ministério do Meio Ambiente, a importância do SISNAMA em suas três esferas e a necessidade de estruturação para um maior fortalecimento a nível municipal. A importância do conhecimento das leis ambientais 
e das políticas públicas do município foi ressaltada e, ainda, no desenvolvimento de práticas pedagógicas desenvolvidas nas escolas municipais, a ampliação de conhecimento adquirido, que permitiu a implantação de ações que possibilitaram um contexto melhor na condução das atividades locais, a exemplo, da instauração da coleta seletiva nos conjuntos habitacionais, melhor atuação nos procedimentos de licenciamento ambiental, reconhecimento que a gestão organizada e compartilhada é a base para a melhoria da qualidade ambiental.

Com relação à utilização dos conhecimentos do PNC na área que atuava na época, 32 dos entrevistados responderam (48\%), a exemplo do entrevistado n.25:

Com certeza, elaborei o projeto de ação, código municipal de meio ambiente e participei de todas as oficinas de resíduos sólidos. Foi muito importante, pena que os gestores não estão dando muita importância as questões ambientais. (Feminino, ensino superior completo, trabalha há 3 anos na área ambiental).

Os outros afirmaram que empregaram o conhecimento na análise de processos junto ao grupo de licenciamento do município e por meio do acompanhamento, junto aos técnicos da SEMARH, nos processos de mobilização dos atores municipais em reuniões para o acompanhamento de estruturação municipal, na elaboração da Agenda 21 e do Código Municipal de Meio Ambiente e no processo de inserção do município no Consórcio de Resíduos Sólidos. Estes, por sua vez, trabalham há mais de cinco anos na área ambiental e possuem formação em engenharia ambiental, agronômica e ciências biológicas.

\subsection{Desdobramentos na gestão ambiental municipal após o Programa Nacional de Capacitação}

Quando questionados se o PNC trouxe avanço na gestão ambiental do município, 38 (57\%) entrevistados responderam à questão, como podemos ver em uma das afirmações transcrita a seguir:

Sem dúvida, após a capacitação foi criada a secretaria de meio ambiente do município, e a partir daí, a lei foi praticada com mais rigor. (Masculino, Engenharia Civil, atuava na época no município de Itabaiana e trabalha há mais de 5 anos na área ambiental).

Tal afirmação pode ser verificada por meio da notícia veiculada pela agência de notícias Infonet em 24 de abril de 2011. Nessa data, a agência divulga a assinatura do convênio junto à SEMARH, que autoriza a Prefeitura de Itabaiana a exercer as atividades de licenciamento ambiental no município (INFONET, 2011). O mesmo procedimento ocorreu recentemente em notícia veiculada pelo site A8 Sergipe (2014), em 9 de abril de 2014, o prefeito de Aracaju, assina o mesmo convênio com a SEMARH.

Para os entrevistados que possuem ensino superior completo e trabalham há mais de 5 anos na área ambiental, a gestão ambiental do município avançou de forma significativa após o PNC, inclusive, alguns projetos foram colocados em ação, houve a possibilidade de fazer licenciamentos simplificados, maior desenvolvimento em projetos de arborização urbana, oficinas de reciclagem e a realização de trilhas ecológicas para os estudantes do município.

Por outro lado, alguns entrevistados afirmaram que não houve avanço, uma vez que a gestão da época não colocou em prática e os que foram capacitados não puderam desenvolver nenhuma atividade, a não ser em seu próprio benefício.

A partir dos relatos dos entrevistados, verificou-se que alguns demonstraram vontade de colocar em prática tudo que aprenderam durante o PNC, porém a própria gestão limitou tal iniciativa. As respostas dos entrevistados a seguir, evidenciam os questionamentos citados anteriormente.

Não teve avanço, faltava o apoio da gestão. (Feminino; pedagogia; trabalhava no município de General Maynard na época do curso).

Por um período, com a mudança de gestão ficou difícil saber até se a Secretaria de Meio Ambiente existia. (Feminino; educação em campo; atuava no município de Cumbe; trabalha há mais de 5 anos na área ambiental).

Quando questionados sobre importância desses passos, dos 67 entrevistados, 59 (88 \%) responderam a questão. Constatou-se que todos os possuem ensino superior completo e trabalham há mais de 5 anos na área ambiental. 
Estes afirmaram que a capacitação proporcionou um maior conhecimento para os gestores municipais, maior entendimento acerca da estrutura do SISNAMA, também aprenderam como estruturar e fortalecer a gestão ambiental municipal e maior conhecimento da política ambiental.

Outro passo citado foi o CGL que viria a facilitar as liberações e as implementações de políticas públicas voltadas para as questões ambientais e as trocas de conhecimento e intercâmbio de experiências aumentaram a percepção dos gestores acerca da criação do comitê gestor local mais dinâmico.

\section{Considerações finais}

Com base nos resultados, constatou-se que a grande parte dos entrevistados alegou possuir ensino superior completo em diversas áreas. No entanto convém ressaltar que nem todos os entrevistados que afirmam possuir experiência na área ambiental, possuem formação específica nessa área.

No tocante ao grau de satisfação dos participantes, constatou-se que $43,3 \%$ classificaram o programa como bom, o mesmo valor foi apontado como ótimo e apenas $13,4 \%$ classificaram como regular. Quanto às mudanças na gestão ambiental municipal, não foi possível quantificar, porém alguns avanços foram apontados.

Para alguns entrevistados, o Programa Nacional de Capacitação trouxe avanço na gestão ambiental do município. Em contrapartida, outros mencionaram que não puderam colocar em prática o que aprenderam com o Programa por conta de empecilhos da própria gestão, o que mostra dessa forma as diferentes prioridades da gestão de cada município do Estado.
Por fim, é de extrema relevância que haja programas de capacitações contínuas, já que existem exonerações por conta do término das gestões, bem como uma definição e detalhamento quanto ao perfil dos gestores participantes. Assim, a gestão atual das prefeituras deve ser sensibilizada quanto à relevância da questão ambiental.

\section{Referências}

A8SERGIPE [site]. 2014. Prefeitura de Aracaju fica responsável pelo licenciamento ambiental do município. Disponível em: <http:/ / a8se.com/conteudo/58/39552/prefeiturade-aracaju-fica-responsavel-pelo-licenciamentoambiental-do-municipio.html>. Acesso em: 29 jul. 2014.

ANTON, C. B. Gestão Ambiental Pública: estudo exploratório na administração municipal de Estância Velha. 2007. Trabalho de Conclusão de Curso (Graduação em Administração) - Universidade Federal do Rio Grande do Sul, Porto Alegre, RS. Disponível em: <http://www.lume. ufrgs.br/bitstream/handle/10183/22110/000647506. pdf? sequence=1\&locale=pt_BR>. Acesso em: $1^{\circ}$ set. 2013.

BARBETTA, Pedro Alberto. Estatística Aplicada às Ciências Sociais. 6. ed. Florianópolis: Editora UFSC, 2006.

BARDIN, Laurence. Análise de conteúdo. ed. ver. e ampl. Lisboa, Portugal: Edições 70, 2011.

BRASIL. Constituição da República Federativa do Brasil de 1988. Artigo 225. Disponível em: < http:/ / www.planalto. gov.br/ccivil_03/constituicao/constituicaocompilado. htm>. Acesso em: 24 jan. 2014.

DARÓS, Tatiane D. Avaliação do Programa Nacional de Capacitação de Gestores Ambientais - PNC: um estudo de caso no estado do Paraná. 2011. Dissertação (Mestrado em Organizações e Desenvolvimento) - FAE - Centro Universitário, Curitiba, PR.

INFONET cidade [site]. 2011. Itabaiana terá órgão licenciador do meio ambiente. Disponível em: <http:/ / www. infonet.com.br/cidade/ler.asp?id=112447>. Acesso em: 29 jul. 2014.

SERGIPE. Secretaria de Estado do Planejamento de Sergipe - SEPLAN. Mapa territórios sergipanos. Aracaju: GIGEC/SUPES/SEPLAN, 2007. Disponível em: <http://www.sedurb.se.gov.br/modules/ wfdownloads / singlefile.php?cid=1\&lid=32>. Acesso em: 30 jun. 2014. 